\title{
A dignidade da humanidade e os deveres em Kant ${ }^{1}$
}

\author{
The dignity of humanity and the duties in Kant's work
}

\begin{abstract}
Milene Consenso Tonetto
Doutora em Filosofia pela Universidade Federal de Santa Catarina (UFSC), professora adjunta da Universidade Federal de Santa Catarina (UFSC), Florianóplis, SC - Brasil, e-mail: mitonetto@yahoo.com.br
\end{abstract}

\section{Resumo}

Este artigo tem por objetivo discutir a plausibilidade de duas críticas endereçadas à ética de Kant. A primeira é que a Ética de Kant é puramente formalista, e a segunda é que, justamente por esse formalismo, a Ética de Kant negligencia o papel das virtudes. Dentro do pensamento Ético, é possível partir do princípio de que a dignidade da humanidade fornece conteúdo para a fundamentação dos direitos humanos e para a elaboração de uma doutrina de virtudes (ethica, no sentido de Kant). Desse modo, sustenta-se que o próprio projeto de uma Metafísica dos Costumes de Kant pode responder as objeções anteriormente mencionadas.

Palavras-chave: Dignidade da humanidade. Direitos. Deveres.

1 Esse trabalho constitui parte dos resultados obtidos nas investigações do meu projeto atual de pesquisa intitulado 0 conceito de dignidade na Ética de Kant. 0 interesse pelas questões abordadas nesse projeto certamente foram influenciadas pelos estudos realizados nas disciplinas ministradas pelo professor Valério Rohden (2008/2) e pela sua co-orientação durante 0 meu doutoramento na UFSC. 


\section{Abstract}

This main aim of this study is to discuss the plausibility of two criticisms generally addressed to Kant's Ethics. The first one is that Kant's Ethics is purely formalist, and the second criticism is that, precisely because of this formalism, Kant's Ethics neglects the role of virtue in moral life. It holds that the dignity of humanity brings content to the justification of the human rights and helps to build up a Doctrine of Virtue (ethica, in Kant's sense). In this way, it concludes that Kant's project of a Metaphysics of Morals can answer the objections mentioned above.

Keywords: Dignity of humanity. Rights. Duties.

\section{Considerações iniciais}

A filosofia moral de Kant tem recebido várias críticas e dentre elas podem-se destacar as seguintes: (i) a de ser meramente formal ${ }^{2}$, e (ii) a de basear-se exclusivamente em regras negligenciando o papel do caráter e das virtudes ${ }^{3}$. Este artigo parte dessas críticas para investigar se o projeto de uma Metafísica dos Costumes, de Kant, pode refutar essas objeções. O que se pretende defender é que o conceito de dignidade, que está ligado ao princípio da humanidade na filosofia moral de Kant, tem um papel na fundamentação dos deveres e fornece conteúdo à elaboração de uma doutrina de virtudes. Por conseguinte, neste trabalho, mostraremos como a dignidade da humanidade fornece conteúdo à ética de Kant.

\section{0 conceito de dignidade da humanidade}

Uma das ideias principais nas discussões éticas, especialmente na área da ética aplicada, é a de que cada pessoa merece uma consideração

\footnotetext{
2 Hegel afirma, no $\$ 135$ de Princípios da Filosofia do Direito, que a ética kantiana do "dever pelo dever" leva a um vão formalismo. De fato, o Imperativo Categórico é uma fórmula, mas isso não significa, como este artigo pretende investigar, que a ética kantiana não tenha conteúdo.

3 MacIntyre, em After Virtue, afirma que a modernidade fazia depender da justificação da virtude uma justificação prévia de regras e princípios e que se tornou problemática sendo incapaz de fundamentar a moralidade (MacINTYRE, A. After Virtue. A study in moral theory. London: Duckworth, 1981. p. 119).
} 
moral básica graças ao valor intrínseco ou dignidade que ela possui. A teoria ética de Kant pode fornecer uma defesa para essa posição. Nesta seção, iremos nos ocupar em mostrar como esse autor chega ao valor inalienável da humanidade ou dignidade da humanidade.

Em primeiro lugar, deve-se esclarecer que, na Fundamentação da Metafísica dos Costumes (GMS, 1785) ${ }^{4}$, Kant estabelece o princípio supremo da moralidade por ele chamado "Imperativo Categórico" e apresenta diferentes formulações para este princípio. Dentre elas, destaca-se a Fórmula do Fim em Si ou Fórmula da Humanidade, em que Kant indica algo especial em relação às pessoas, algo que as fazem ser merecedoras de uma especial consideração moral.

O Imperativo Categórico é um princípio capaz de estabelecer leis práticas, isto é, leis morais no sentido de um imperativo categórico que ordena uma ação como válida em si mesmo ${ }^{5}$. Segundo ele, a máxima da minha ação (princípio subjetivo do querer) deve ser submetida a um teste a fim de torná-la uma regra objetiva ou universal. A fórmula geral do Imperativo Categórico é apresentada nos seguintes termos: "Age apenas segundo uma máxima tal que possas ao mesmo tempo querer que ela se torne lei universal" (GMS, AA 4, p. 420). Para Kant, a ação terá valor moral somente se ela for realizada por respeito a essa lei universal. Como se pode perceber, a primeira fórmula do princípio consiste num teste completamente formal. Mas isso não pode ser sustentado em relação à Fórmula do Fim em Si. Nela, Kant introduz a noção de humanidade da seguinte maneira: "Age de tal modo que uses a humanidade, tanto na tua pessoa como na pessoa de qualquer outro, sempre e simultaneamente como fim e nunca simplesmente como meio" (GMS, AA 4, p. 429) ${ }^{6}$. Essa formulação do Imperativo Categórico requer uma coisa aparentemente simples e clara, a saber, que tratemos a humanidade, em nós mesmos e nos outros, sempre como um fim em

\footnotetext{
4 Ver sistema de abreviações das obras de Kant na bibliografia.

5 Nesse trabalho, o princípio supremo da moralidade chamado por Kant de "Imperativo Categórico" será escrito com iniciais em letra maiúscula. Por outro lado, os princípios testados pelo Imperativo Categórico devem ser chamados de imperativos categóricos com iniciais em letra minúscula.

6 Segundo TUGENDHAT, E. Lições de ética. Petrópolis: Vozes, 1993. p. 83, a Fórmula do Fim em Si é a mais importante da ética de Kant e expressa conteúdos morais.
} 
si mesmo. Por esse motivo, ela parece ter entre os leitores de Kant um forte apelo moral. Mas, como veremos, a ideia de "humanidade" e o que está envolvido no tratamento da humanidade como um "fim em si mesmo" não são suficientemente esclarecidos pelo filósofo e os comentadores de sua teoria possuem diferentes interpretações. A seguir, nos ocuparemos com a explicitação desses elementos.

Poderia parecer óbvio que Kant estivesse usando "humanidade" para se referir a todos os seres humanos, de modo que devêssemos tratar todos eles (e somente eles) como fins em si mesmos. Mas isso, segundo especialistas da ética de Kant, não está correto. Por exemplo, Richard Dean aponta que há uma posição padrão entre os comentadores que defendem que a humanidade refere-se a um conjunto de características que algum ser minimamente racional possui. Nesse contexto, ele cita Allen Wood, segundo o qual a humanidade pertence a todos os membros maduros da nossa espécie biológica. Ele chama essa interpretação de minimal readings of humanity (DEAN, 2006, cap. 2). Mesmo assim, como veremos, há divergências substanciais sobre quais seriam essas propriedades.

Segundo Dean, a minimal readings pode ser dividida em três categorias. "A primeira categoria identifica a humanidade simplesmente como o poder de estabelecer fins ou fazer escolhas - em outras palavras, como Willkür" (DEAN, 2006, p. 25). Esse é um domínio que todos os seres racionais possuem, segundo a posição de Kant sobre a natureza racional. Ter uma vontade é a característica que define os agentes racionais. Segundo Kant, Willkür e Wille são os dois elementos básicos da vontade. Desse modo, todo agente racional tem o poder de estabelecer fins para ele mesmo. De fato, o conceito de humanidade é definido na GMS como a capacidade de estabelecer fins: "a natureza racional distingue-se das restantes por se pôr a si mesma um fim" (GMS, AA 4, p. 437). Segundo Christine Korsgaard, nesta obra, Kant alterna o uso de humanidade com natureza racional (KORSGAARD, 1996, p. 110). Mas, segundo ela, a passagem completa que expressa essa noção de humanidade é encontrada na MS. Ali, Kant afirma que "a capacidade de em geral se propor um fim, qualquer que ele seja, é o que constitui o elemento característico da humanidade (ao invés da animalidade)" 
(TL, AA 6, p. 392). Ao fim da humanidade, na nossa própria pessoa, está associada também a vontade racional e, por conseguinte,

o dever de se tornar digna da humanidade mediante a cultura em geral, o dever de buscar ou de promover a capacidade de realizar quaisquer fins possíveis, na medida em que esta faculdade só no homem é suscetível de ser encontrada (TL, AA 6, p. 392).

Segundo Korsgaard, essas passagens indicam que Kant entende a humanidade como a capacidade para estabelecer fins para as ações.

A segunda categoria da minimal readings, de acordo com Dean, identifica a humanidade com um conjunto maior de características próprias da racionalidade. Além da Willkür, as características adicionais que são propostas incluem o poder de legislar princípios morais para si mesmo (Wille), o poder de agir de acordo com imperativos hipotéticos, a habilidade de comparar vários fins contingentes e organizá-los em um todo sistemático e a habilidade de empregar a razão teórica para entender o mundo. A ideia dessa segunda categoria é que a humanidade é equivalente a um grupo de características pessoais ou habilidades que todos os seres minimamente racionais possuem. E assim, qualquer ser minimamente racional deve ser tratado como fim em si mesmo. Segundo Dean, a posição defendida por Allen Wood se enquadra nessa segunda categoria. Wood identifica a humanidade com a capacidade de estabelecer fins e mais outras capacidades associadas com esta habilidade, por exemplo, a capacidade de organizar esses fins num todo sistemático. Segundo ele, "a humanidade claramente pertence a todos os membros maduros de nossa espécie biológica que não estão severamente incapacitados" (WOOD, 1999, p. 119).

A terceira categoria identifica a humanidade com a capacidade de agir moralmente. Tal capacidade para a moralidade deve ser distinguida da posse de um real comprometimento de agir como a moralidade requer. Segundo Dean, os comentadores falham em não especificarem exatamente o que eles acham que constitui a capacidade de agir moralmente. Aceitar os princípios morais como um determinante de suas ações requer a habilidade de escolher entre as ações, ou Willkür. Por sua vez, isso requer o acesso a princípios morais algo que segundo Kant é 
fornecido pela Wille, ou capacidade que cada agente possui para legislar seguindo princípios morais. Para uma vontade santa ou perfeita, esses ingredientes poderiam ser suficientes para levar até as ações morais. Mas para seres como os humanos que estão sujeitos às inclinações, deve haver também algum sentimento que acompanha a escolha de agir segundo leis morais. Segundo Dean, na GMS e KpV, Kant (2006, p. 26) explica o papel que os sentimentos particulares têm em tornar possível aos seres humanos agir puramente segundo princípios morais. Reverência (Achtung) e a predisposição para a personalidade são os sentimentos necessários. A reverência é um sentimento que surge quando nós apreendemos a razão que dá força à lei moral e como nossas inclinações perdem a importância comparado com os requerimentos morais. Kant distingue reverência de outros sentimentos tipicamente humanos, pois não é de origem empírica, mas, ao invés disso, é produzido por uma base intelectual, a saber, o reconhecimento do poder incondicional dos princípios morais de comandar. Alguém poderia pensar que este sentimento de reverência seria o suficiente para levar os seres humanos a agirem segundo o motivo do dever. Mas na RGV, segundo Dean, Kant sustenta algo aparentemente contrário a isso quando afirma que precisamos de uma predisposição natural adicional cujo papel serviria como uma base subjetiva para incorporar o respeito como uma força motivadora de nossas máximas (RGV, AA 6, p. 27). Isto é o que Kant chama de predisposição para a personalidade e diz que é um sentimento moral. Contudo Kant define respeito na GMS como um sentimento subjetivo "que se produz por si mesmo através dum conceito da razão" (GMS, AA 4, p. 401). Assim, não fica claro porque o respeito só pode ter influência subjetiva por um outro sentimento moral. O que fica claro é que, para os seres racionais imperfeitos terem capacidade de agir moralmente, é necessário não somente a posse da Wilkür e Wille, mas também a posse de um sentimento moral que os levem a agir de acordo com o que a Wille deseja. Segundo Dean (2006, p. 30), Thomas E. Hill defende a humanidade de acordo com a terceira classificação. Ele identifica a humanidade com uma gama mais ampla de habilidades racionais incluindo, por exemplo, a capacidade de legislar e agir de acordo com leis morais, de seguir princípios de prudência (imperativos hipotéticos) (HILL, 1992, p. 40). 
Antes de explicitarmos melhor o conceito kantiano de dignidade, convém fazer uma observação crítica sobre a interpretação chamada minimal readings. De alguma maneira, o fato de pertencer a nossa espécie parece nos privilegiar em relação a outros seres. É importante, então, deixarmos claro que Kant não é um especista, no sentido de reservar um valor especial aos seres humanos, por pertencerem meramente à espécie Homo sapiens. Kant diz que a "humanidade", ou melhor, a natureza racional em uma pessoa é o que possui valor como um fim em si mesmo e essa racionalidade pode ser tida por outros seres, não somente aos que pertencem à nossa espécie. Outros seres racionais não sensíveis (anjos, se existirem) ou eventuais habitantes racionais de outros planetas ou membros de alguma outra espécie também podem ser racionais e, por conseguinte, representarem-se como fins em si. Por conseguinte, como veremos, teriam dignidade.

Tendo apresentado as diferentes interpretações dadas ao conceito de humanidade, precisamos agora entender porque Kant afirma que se deve tratar a humanidade de uma pessoa como um fim em si mesma e não como um mero meio. De acordo com Kant, todos os seres racionais estão submetidos à lei que ordena que cada um deles jamais se trate a si mesmo ou aos outros "simplesmente como meios, mas sempre simultaneamente como fins em si". Disso resulta

uma ligação sistemática de seres racionais por meio de leis objetivas comuns, isto é, um reino que, exatamente porque estas leis têm em vista a relação destes seres um com os outros como fins e meios, se pode chamar um reino dos fins (GMS, AA 4, p. 433).

Para esclarecer esse ponto, é necessário discutir o conceito de dignidade. No reino dos fins, isto é, na comunidade em que todas as pessoas se tratam como fins em si mesmas tudo tem um preço ou uma dignidade. "Quando uma coisa tem um preço, pode-se pôr em vez dela qualquer outra como equivalente; mas, quando uma coisa está acima de todo o preço e, portanto, não permite equivalente, então ela tem dignidade [Würde]". (GMS AA 4, p. 434). Kant sustenta que a condição para algo ser considerado um fim em si mesmo é a de possuir dignidade: "Aquilo [...] que constitui a condição só graças à qual qualquer coisa 
pode ser um fim em si mesma, não tem somente um valor relativo, isto é, um preço, mas um valor íntimo, isto é, dignidade" (GMS, AA 4, p. 435) ${ }^{7}$. E acrescenta: "A moralidade é a única condição que pode fazer de um ser racional um fim em si mesmo [...] Portanto, a moralidade, e a humanidade enquanto capaz de moralidade, são as únicas coisas que tem dignidade" (GMS, AA 4, p. 435), isto é, "um valor incondicional, incomparável, cuja avaliação, que qualquer ser racional sobre ele faça, só a palavra respeito pode exprimir convenientemente. Autonomia é pois o fundamento da dignidade da natureza humana e de toda a natureza racional" (GMS, AA 6, p. 436). Desse modo, deve-se tratar a humanidade enquanto fim em si mesma porque ela possui dignidade.

O ser humano não é uma coisa e, por isso, não pode ser utilizado arbitrariamente pela vontade dos outros. Nesse sentido, não se pode dispor do homem na minha pessoa para mutilá-lo, degradá-lo ou matá-lo. Segundo Kant, o conflito com o princípio da humanidade de um indivíduo torna-se ainda mais claro

quando tomamos para exemplos ataques à liberdade ou à propriedade alheias. Porque então é evidente que o violador dos direitos dos homens [Rechte der Menschen] tenciona servir-se das pessoas dos outros simplesmente como meios, sem considerar que eles, como seres racionais, devem ser sempre tratados ao mesmo tempo como fins [...] (GMS AA 4, p. 430[negritos acrescentados]).

Poderíamos dizer também que tratar um indivíduo meramente como um meio constitui uma violação dos direitos humanos. A condição para algo ser tratado como um fim em si mesmo é a de possuir dignidade. Pode-se, portanto, visualizar que, na teoria kantiana, os direitos estão vinculados com a defesa da dignidade.

Segundo Onora O’Neil, “usar alguém como um mero meio é envolvê-lo num esquema de ação ao qual ele não pode em princípio

\footnotetext{
7 É interessante contrastar aqui a definição de dignidade de Kant com a de Hobbes. Para este, "0 valor público de um homem, aquele que Ihe é atribuído pelo Estado, é o que os homens vulgarmente chamam dignidade. E esta sua avaliação pelo Estado se exprime a partir de cargos de direção, funções judiciais e empregos públicos, ou pelos nomes etítulos introduzidos para a distinção de tal valor" (HOBBES, T. Leviatã ou matéria, forma e poder de um estado eclesiástico e civil. São Paulo: Abril Cultural, 1979. p. 54). Como pode ser visto, a dignidade para Hobbes não é uma propriedade inerente à pessoa, mas algo atribuído externamente.
} 
consentir" (O’NEILL, 2010, p. 448). Kant não diz que há algo errado em usar alguém como um meio. Evidentemente, nós temos que fazer isso em cada esquema cooperativo de ação. "Se eu desconto um cheque, eu uso o contador como um meio, sem o qual eu não poderia colocar minhas mãos no dinheiro e o contador, por outro lado, me usa como um meio para receber o seu sustento" (O’NEILL, 2010, p. 448). Mas, neste caso, cada parte consente com a transação. Segundo a autora, Kant diria que, embora nós nos usemos uns aos outros como meios, nós não estamos nos usando como meros meios.

Há outras situações, de acordo com O’Neill, em que uma pessoa usa a outra de um modo que ela não poderia em princípio consentir. Por exemplo, uma pessoa poderia fazer uma promessa à outra com todas as intenções de quebrá-la. Se a promessa for aceita, então a pessoa a quem ela foi feita ignora qual é a verdadeira máxima de quem fez a promessa. Se alguém sabe que aquele que faz uma promessa não tem a intenção de fazer o prometido, então, ele não vai aceitar ou confiar na promessa. De modo contrário, seria como se não tivesse sido feito promessa alguma. A promessa falsa terá êxito somente a partir do engano de outra pessoa. E visto que a pessoa que foi enganada não conhece a máxima real, ele ou ela não pode em princípio consentir com a sua parte no esquema proposto de ação. "A pessoa que é enganada é, tal como aconteceu, uma escora ou um instrumento - um mero meio - para o esquema do falso prometedor" (O'NEILL, 2010, p. 448). Uma pessoa que faz uma promessa falsa manipula o outro, trata-o como uma coisa e não como uma pessoa.

Segundo O'Neill, outro modo de usar os outros como meros meios é pela coerção. Se uma pessoa rica ou poderosa ameaça um devedor com a bancarrota, a menos que ele se junte em algum esquema, então, nesse caso, a intenção do credor é coagir e o devedor, se coagido, não pode consentir com a sua parte no esquema do credor. Na perspectiva de Kant, as ações que são feitas a partir de máximas que requerem engano ou coerção sobre os outros e assim não podem ter o consentimento deles, pois o consentimento previne tanto o engano quanto a coerção, são errados. Quando agimos sob tais máximas, nós tratamos os outros como meros meios, como coisas ao invés de fins em si mesmos. Se nós agimos 
a partir de tais máximas, nossos atos não são apenas errados, mas injustos: tais atos usam os outros que são enganados e coagidos.

Mas há casos também em que, embora não usemos os outros como meros meios, ainda assim nós falhamos em usá-los como fins em si mesmos. Segundo O’Neill, "tratar alguém como um fim em si requer, em primeiro lugar, que não se use ele ou ela como um mero meio, que se respeite cada pessoa racional com suas próprias máximas" (O’NEILL, 2010, p. 449). Alguém pode também procurar fomentar os planos dos outros e suas máximas compartilhando os seus fins. Agir de modo beneficente é procurar a felicidade dos outros, portanto tentar alcançar algumas das coisas que os outros estão tentando com suas máximas. Se eu quero fazer os outros felizes, vou adotar as máximas que não meramente não os manipulam, mas que incrementam alguns de seus planos e atividades. As ações beneficentes tentam alcançar o que os outros querem. Todavia não podemos procurar tudo o que os outros querem, pois suas vontades são tão numerosas e diversas e, certamente, algumas vezes tornam-se incompatíveis. Segue-se que a beneficência deve ser seletiva. Na próxima seção, iremos discutir, de forma mais aprofundada, essa questão, a saber: se tratar uma pessoa como um fim em si mesma, pode gerar deveres positivos e não apenas deveres negativos.

\section{Dignidade da humanidade e a derivação de deveres}

Uma proposta de derivação dos deveres a partir da humanidade é apresentada por Guyer em Kant's System of Duties. Segundo ele, a humanidade definida como a habilidade de estabelecer os próprios fins é a "forma fundamental do exercício da liberdade de escolha" (GUYER, 2005, p. 250). Do mesmo modo, "a capacidade de realizar ou perseguir os fins livremente escolhidos é a forma fundamental da liberdade de ação". Para Guyer, o comando de sempre tratar a humanidade como fim e nunca meramente como um meio é o reconhecimento do valor incondicional da liberdade. Assim a forma mais geral de nossa obrigação moral é a de preservar e promover a possibilidade da liberdade de escolha e ação em nós mesmos e nos outros. 
De fato, na GMS, Kant relaciona o princípio da humanidade com a liberdade de ação, indicando previamente a origem do princípio do direito. Segundo ele, "este princípio da humanidade e de toda a natureza racional em geral como fim em si mesma (é a condição suprema que limita a liberdade das ações de cada homem)" (GMS, AA 4, p. 431). $\mathrm{O}$ dever de tratar a humanidade como fim em si mesma implica que se deve limitar a liberdade de ação de cada homem. É exatamente isso que o princípio universal do direito estabelece, a saber, que "é justa toda ação segundo a qual ou segundo cuja máxima a liberdade do arbítrio de cada um pode coexistir com a liberdade de qualquer um segundo uma lei universal" (RL, AA 6, p. 230). Em outros termos, a ação justa é aquela que torna possível a coexistência da liberdade de todos. Todo direito consistirá na limitação da liberdade de alguém a fim de tornar a coexistência da liberdade de todos possível de acordo com uma lei universal. Desse modo, Kant defende que a liberdade é um "direito único, originário, pertencente a cada homem por força de sua humanidade" (RL, AA 6, p. 237). Nota-se, aqui, o conceito de humanidade fundamentando o único direito inato kantiano. A preservação da sua própria humanidade e a dos outros tanto quanto a busca de fins livremente escolhidos irá requerer que o ser humano seja capaz de mover livremente seu corpo. Desse modo, o dever geral de tratar a humanidade, enquanto capacidade de liberdade de escolha e ação, como um fim em si mesma e não como um mero meio irá estabelecer que se deve encontrar maneiras de regular os movimentos do próprio indivíduo e o uso dos outros corpos a fim de preservar a liberdade, não somente a sua liberdade, mas também a liberdade dos outros. Os deveres gerais de preservar a liberdade dos indivíduos e a possibilidade do exercício dessa liberdade, tanto quanto a realização dos fins que são livremente escolhidos pelos indivíduos irão requerer a regulação do uso do corpo da própria pessoa e dos outros para respeitar a humanidade de todos. De acordo com Guyer, até mesmo a discussão na $R L$ acerca do direito privado sustenta que o direito de propriedade pode ser derivado a partir da humanidade como fim em si mesma (GUYER, 2005, p. 257). Isso porque a principal afirmação da teoria dos direitos de propriedade de Kant é que os seres humanos são criaturas 
personificadas que dependem do movimento livre dos corpos. A manutenção dos corpos exige que se tenha direito de adquirir os objetos necessários à sobrevivência.

A Fórmula do Fim em Si não apenas permite justificar deveres jurídicos, mas também deveres de virtude. Já na GMS, Kant usa diversos exemplos de deveres para aplicar o Imperativo Categórico na sua formulação do "Fim em Si". Kant escolhe os exemplos "da divisão habitual em deveres para com nós mesmos e deveres para com os outros, em deveres perfeitos e imperfeitos" (GMS, AA 4, p. 421). Ele fornece um exemplo para cada uma das quatro classes de deveres que são derivados a partir dessas duas divisões. Para ilustrar os deveres perfeitos para consigo, Kant usa o dever de proibição do suicídio. Como exemplo de deveres perfeitos para com os outros, ele cita o dever de não fazer promessas falsas, isto é, promessas que alguém não poderá manter. Para exemplificar os deveres imperfeitos para consigo, ele menciona o dever de cultivar as predisposições naturais que os indivíduos têm para habilidades e talentos. E em relação aos deveres imperfeitos para com os outros, Kant considera o dever de beneficência ou cuidado mútuo (GMS, AA 4, p. 422).

Segundo Guyer, ao se considerar a definição de humanidade como capacidade de estabelecer e tentar realizar livremente certos fins pode-se derivar os quatro exemplos de deveres da GMS a partir da proposição de sempre se tratar a humanidade como um fim e nunca meramente como um meio (GUYER, 2005). Por exemplo, o dever de não cometer suicídio é obviamente um caso de um dever geral de não destruir um ser capaz de fazer escolhas livres. Do mesmo modo, a proibição de homicídio deve ser feita, pois não se deve destruir um agente livre. Existem outros exemplos dessa classe geral de deveres, não só em relação aos outros, mas também em relação consigo mesmo, por exemplo, o dever de evitar a embriaguez (TL, AA 6, p. 427). Ele pode ser entendido como um dever de não comprometer a habilidade de exercer a liberdade de escolha durante um período de intoxicação. Também o dever de cultivar os talentos pode ser considerado um dever de desenvolver as condições gerais que irão facilitar a realização de fins particulares que alguém pode livremente estabelecer no exercício de 
sua humanidade. $\mathrm{O}$ dever de beneficência pode ser entendido como o dever de dar assistência aos outros na realização de certos fins que um indivíduo livremente estabeleceu. Aparentemente, esse é um modo de conceber positivamente o dever de tratar a humanidade como fim em si.

Pode-se, então, sustentar que tratar a humanidade como um fim em si mesma permite derivar deveres para promover fins particulares que alguém escolhe. Mas isso pode parecer um dever de alcançar a felicidade, algo que precisa ser qualificado. Certamente, Kant não é um utilitarista. Na introdução da TL, Kant argumenta que não se pode ter um dever direto de promover a sua própria felicidade. Isso porque o dever requer a superação de uma aversão e, certamente, a felicidade própria não pode ser assim caracterizada (TL, AA 6, p. 387-8). Contudo, Kant também considera que alguém pode ter um dever indireto de tornar a si mesmo feliz o suficiente a fim de evitar a tentação de fazer algo imoral (TL, AA 6, p. 387-8). Segundo Korsgaard, na GMS, o argumento da Fórmula da Humanidade ${ }^{8}$ é precedido pela advertência de que o motivo que se está procurando não pode ser derivado de uma "disposição natural particular da humanidade, de certos sentimentos e tendências, mesmo até, se possível, de uma propensão especial que seja própria da razão humana e não tenha que valer necessariamente para a vontade de todo o ser racional" (GMS, AA 4, p. 425). Desse modo, segundo a comentadora "deve resultar que agir livremente por dever e adotar a humanidade como um fim incondicionado são uma única e mesma coisa" (KORSGAARD, 1996, p. 109).

Uma importante conexão que deve ser observada é a seguinte: ao analisar o quarto exemplo de máxima na GMS a partir da Fórmula do Fim em Si do Imperativo Categórico, Kant afirma que, no concernente ao dever meritório para com outrem, o fim natural que todos os homens têm é a sua própria felicidade. A humanidade poderia subsistir se ninguém contribuísse para a felicidade dos outros, contanto que também não se subtraísse nada intencionalmente. Nas palavras dele,

Mas se cada qual se não esforçasse por contribuir na medida das suas forças para os fins dos seus semelhantes, isso seria apenas uma

8 Korsgaard chama a "Fórmula do Fim em Si" de "Fórmula da Humanidade" (KORSGAARD, C. Creating the Kingdom of Ends. New York: Cambridge University Press, 1996. p. 109). 
concordância negativa e não positiva com a humanidade como fim em si mesma. Pois que se um sujeito é um fim em si mesmo, os seus fins têm de ser quanto possível os meus, para aquela ideia poder exercer em mim toda a sua eficácia (GMS, 4, p. 430).

A partir dessa argumentação, pode-se defender que o dever de respeitar a humanidade em sua dignidade gera deveres positivos e não apenas deveres negativos. A Fórmula do Fim em Si exige que se leve em conta os projetos de vida ou os fins que outros indivíduos querem alcançar. Não poderíamos cumprir esse dever sendo somente indiferente às outras pessoas. Agora, se a dignidade está relacionada com o reconhecer e com o tratar o ser humano como fim em si e isto implica não apenas não ferir a sua liberdade, algo puramente negativo, mas levar positivamente os seus fins em consideração, talvez seja possível justificar kantianamente uma série de direitos sociais e econômicos. Além disso, permite ver claramente que há deveres para com os outros, mesmo que imperfeitos de fomentar o bem estar deles.

Essa posição fundamenta-se, em primeiro lugar, na própria definição de ética sustentada por Kant na Metafísica dos Costumes. Na introdução da Doutrina da Virtude ele afirma que

a ética [...] fornece um conteúdo (um objeto da escolha livre), um fim da razão pura que é representado como um fim que também é objetivamente necessário, isto é, um fim que, na medida em que os seres humanos são considerados, é um dever tê-lo (TL, AA 6, p. 380).

Os deveres de virtude são deveres que fomentam certos fins confirmados pela razão, isto é, deveres que são fins simultaneamente. Esses deveres prescrevem um fim ou um propósito. Para Kant, os fins que também são deveres "são a própria perfeição do indivíduo e a felicidade dos outros" (TL, AA 6, p. 385). Kant cita somente a própria perfeição da pessoa e não a felicidade dela mesma porque a felicidade própria é desejada por impulsos da natureza, não enquanto dever. Do mesmo modo, ele menciona só a felicidade dos outros e não a perfeição dos outros porque a perfeição dos outros consiste na perfeição da moralidade e isso é algo que cada um deve fazer por conta própria. Assim, 
Kant não aceita que o dever de respeitar uma pessoa como um fim em si mesma possa ser cumprido somente sendo indiferente aos outros. Deve-se levar em consideração a felicidade dos outros, isto é, a busca do bem-estar, do vigor, da saúde e da prosperidade em geral. Pode-se também defender que a Fórmula do Fim em Si compreenderá os deveres positivos para conosco, por exemplo, o dever de autorrespeito.

Tendo mostrado como os deveres em geral podem ser derivados da humanidade, trataremos agora de mostrar mais detalhadamente como a Fórmula do Fim em Si se relaciona com o estabelecimento das virtudes. Kant define o princípio supremo da doutrina da virtude do seguinte modo: "Age de acordo com uma máxima dos fins que possa ser uma lei universal para todos terem” (TL, AA 6, p. 395). Ao comentá-lo, Kant torna explícito tratar o ser humano como fim em si: "segundo este princípio, o homem é fim tanto para si mesmo como para os demais e não é suficiente que ele não esteja autorizado a usar-se a si próprio como meio nem a usar como tal os demais" (TL, AA 6, p. 395). Quando Kant apresenta as noções preliminares relativas à divisão da doutrina da virtude, ele retoma essa ideia:

no que diz respeito à matéria, a doutrina da virtude não deve ser estabelecida meramente como uma doutrina do dever em geral, mas também como doutrina dos fins: de tal modo que o homem está obrigado a pensar-se tanto a si mesmo como a qualquer outro homem como fim seu (TL, AA 6, p. 410).

Como se pode perceber, a Fórmula do Fim em Si influencia a elaboração do princípio da doutrina da virtude.

A partir do princípio supremo da doutrina da virtude, que, como foi visto, exige o tratamento da humanidade como um fim em si mesma, Kant deriva uma série de deveres de virtude. É importante esclarecer aqui que há apenas uma obrigação de virtude, a saber, a atitude virtuosa como fundamento subjetivo da determinação de cumprir o próprio dever, mas muitos deveres de virtude, porque há muitos objetos que são fins que, ao mesmo tempo, constituem um dever tê-los como fins. Esses deveres, portanto, refletem o uso comum que se faz da palavra "virtuoso". Para Kant, uma pessoa é considerada virtuosa quando ela 
possui a pureza da atitude. Kant faz algumas considerações sobre a virtude nesse sentido. Ele afirma que, nas circunstâncias reais da existência humana, as pessoas estão sujeitas a obstáculos que impedem o cumprimento do dever e que colocam resistência a esse cumprimento. Segundo Kant, o homem tem que se julgar capaz de combatê-las e vencê-las por meio da razão. Desse modo, "a capacidade e o propósito deliberado de se opor a um adversário poderoso, mas injusto, é a coragem (fortitudo) e, em relação ao adversário da atitude moral que existe em nós, é virtude (virtus, fortitudo moralis)" (TL, AA 6, p. 380).

O dever de tratar a humanidade como fim em si mesma está fortemente conectado com a Doutrina da Virtude, pois pode-se notar a vinculação da ideia da dignidade da humanidade com as virtudes e com os vícios. Num comentário a um vício em particular, a saber, o servilismo, Kant escreve:

somente o homem, considerado como pessoa, isto é, como sujeito de uma razão prático-moral, está acima de todo o preço; pois que, como tal (como homo noumenon), não pode valorar-se apenas como meio para fins alheios, mas sim como fim em si mesmo, isto é, possui uma dignidade (um valor intrínseco absoluto) mediante a qual obriga todos os demais seres racionais do mundo a guardar-lhe respeito, podendo medir-se com qualquer outro desta espécie e valorar-se em pé de igualdade (TL, AA 6, p. 434-435).

Nesse sentido, Kant irá estabelecer que "é a doutrina da virtude a que prescreve considerar como sagrado o direito dos homens" (TL, AA 6, p. 395) ${ }^{9}$.

Kant elenca os deveres de virtude a partir da afirmação de que a ética se ocupa dos fins que são ao mesmo tempo deveres, a saber, a perfeição própria e a felicidade alheia (TL, AA 6, p. 385). A perfeição própria origina os deveres para consigo, tais como o de cultivar as próprias faculdades ou predisposições naturais. A mais alta dessas predisposições é o entendimento, mas também o cultivo da própria vontade para realizar aquilo que é exigido pelo dever. Por exemplo,

\footnotetext{
9 No original: “Denn es ist die Tugendlehre, welche gebietet, das Recht der Menschen heilig zu halten".
} 
um ser humano tem o dever de cultivar a sua natureza e superar sua animalidade em direção à humanidade. Ele tem o dever de instruir-se, de corrigir seus erros, de manter a própria vida, de ser sincero etc. Kant relaciona explicitamente na TL cada um desses deveres com a humanidade. O dever de aumentar a perfeição natural é justificado por Kant do seguinte modo: "é dever do homem para consigo próprio ser um elemento útil para o mundo, porque isto também faz parte do valor da humanidade" (TL, AA 6, p. 423). O dever contra o suicídio está fundamentado na ideia de que se "dispor de si próprio como de um simples meio para um fim qualquer é equivalente a desvirtuar a humanidade na sua própria pessoa” (TL, AA 6, p. 423). Em relação ao dever de ser sincero, Kant afirma que "a mentira é rejeição e, por assim dizer, destruição da própria dignidade do homem" (TL, AA 6, p. 429). Pode-se perceber, assim, que os deveres para consigo mesmo derivam explicitamente da humanidade.

A felicidade alheia origina os deveres em relação aos outros, a saber, os deveres de respeito, de beneficência, de gratidão e de simpatia. Kant chama os três últimos deveres de imperfeitos. Eles são dotados de latitude, ou seja, permitem um espaço de decisão sobre a ação que se fará e sobre o quanto é preciso fazer com vista a um determinado fim. Há também evidências textuais na TL que provam que a fundamentação desses deveres se baseiam na humanidade. Por exemplo, o dever de respeito para com os outros é justificado como "o reconhecimento de uma dignidade (dignitas) nos outros homens, isto é, um valor que não tem preço, que não tem equivalente" (TL, AA 6, p. 462). Kant explica que a humanidade é ela própria uma dignidade, pois o homem não pode ser utilizado meramente como meio por outro homem (nem por outros, nem sequer por si mesmo), tendo de ser sempre utilizado como fim e nisto consiste precisamente sua dignidade (a personalidade). Assim, como não pode alienar-se a si próprio por qualquer preço que seja (o que seria contra o dever de autoestima), tão pouco pode agir contra a autoestima dos outros enquanto homens, ou seja, "está obrigado a reconhecer no plano prático a dignidade da humanidade em todos os outros homens; por conseguinte, impende sobre ele um dever que se refere ao respeito que se há de necessariamente testemunhar a 
qualquer outro homem" (TL, AA 6, p. 463). Assim, todos os deveres de respeito estão fundamentados na dignidade da humanidade. Em relação ao dever de gratidão, Kant afirma que a sua violação ou a prática da ingratidão "é um vício que ofende a humanidade" (TL, AA 6, p. 459). Há ainda o dever de se simpatizar com os outros, isto é, partilhar alegria ou sofrimento e utilizá-los como meios para fomentar a benevolência ativa e racional que é para Kant "um dever especial [...] que tem o nome de humanidade (humanitas): porque o homem é aqui considerado não apenas como um ser racional, mas também como um animal dotado de razão" (TL, AA 6, p. 456). A humanidade pode se situar na faculdade e vontade de comunicar entre si os sentimentos ou simplesmente na receptividade para o sentimento comum de alegria ou de dor que é dada pela própria natureza. Desse modo, Kant consegue também fundamentar o dever de simpatia a partir da humanidade. Esses são os deveres de virtude que, segundo Kant, possuem papel no cumprimento do dever e que estão fortemente relacionados com o fundamento da dignidade da humanidade.

\section{Observações finais}

Neste artigo, foi explicitado o conceito de dignidade da humanidade na teoria de Kant e suas implicações éticas. Basicamente, foi defendido que, a partir da Fórmula do Fim em Si, é possível responder algumas das críticas à moral kantiana. Kant defende os deveres de promover a felicidade alheia e, por isso, a acusação da ética kantiana ser puramente formal não parece ser válida. Os deveres de promover a felicidade dos outros, a saber, beneficência, gratidão, simpatia podem ser denominados deveres positivos, embora sejam imperfeitos. Desse modo, a derivação dos deveres a partir da humanidade mostra que a ética de Kant não se caracteriza como a aplicação meramente formal de regras morais e que ela não se restringe apenas à formulação de deveres negativos.

Outra crítica endereçada a Kant é a de ele não considerar as virtudes e dar muita importância às regras e princípios. Como foi visto, 
Kant considera as virtudes essencialmente importantes para o cumprimento do dever. A virtude é a força (fortitudo moralis) que se opõe aos adversários da atitude moral. Ela é necessária para combater os obstáculos que impedem o cumprimento do dever. Portanto, pode-se defender que a ética de Kant não negligencia totalmente o papel do caráter e das virtudes. Essa é uma resposta que pode ser dada à crítica de que Kant baseia sua ética exclusivamente em regras.

Obras de Kant (Citações de acordo com a Academie-Ausgabe [AA]):

GMS Grundlegung zur Metaphysik der Sitten (AA 04) (Cito tradução de Paulo Quintela: Fundamentação da metafísica dos costumes. Lisboa: Edições 70, 1986).

MS Die Metaphysik der Sitten (AA 06)

RL Metaphysische Anfangsgründe der Rechstlehre (AA 06) (Cito tradução de Joãosinho Beckenkamp. Princípios metafísicos da doutrina do direito. Obra não publicada).

TL Metaphysische Anfangsgründe der Tugendlehre (AA 06) (Cito tradução de José Lamego: Princípios metafísicos da doutrina da virtude. Lisboa: Fundação Calouste Gulbenkian, 2005).

$\mathrm{KpV} \quad$ Kritik der praktischen Vernunft (AA 05)

(Cito tradução de Valério Rohden: Crítica da razão prática. São Paulo: Martins Fontes, 2003).

RGV Die Religion innerhalb der Grenzen der bloßen Vernunft (AA06)

(Cito tradução de Artur Morão: A religião nos limites da simples razão. Lisboa: Edições 70, 1992).

\section{Referências}

DEAN, R. The Value of humanity in Kant's moral theory. New York: Oxford University Press, 2006. 
TONETTO, M. C.

GUYER, P. (Ed.). Kant and the experience of freedom. Cambridge: Cambridge University Press, 1996.

GUYER, P. (Ed.). The Cambridge companion to Kant. Cambridge: Cambridge University Press, 1999.

GUYER, P. (Ed.). Kant on freedom, law, and happiness. New York: Cambridge University Press, 2000.

GUYER, P. (Ed.). Kant's system of nature and freedom: selected essays. Oxford: Clarendon Press, 2005.

HEGEL, F. Princípios da filosofia do direito. São Paulo: M. Fontes, 2003.

HILL, T. Jr. Dignity and practical reason in Kant's moral theory. Ithaca, New York: Cornell University Press, 1992.

HILL, T. Jr. Autonomy and Self-Respect. Cambridge: Cambridge University Press, 1995.

HOBBES, T. Leviatã ou Matéria, forma e poder de um estado eclesiástico e civil. São Paulo: Abril Cultural, 1979.

KORSGAARD, C. Creating the kingdom of ends. New York: Cambridge University Press, 1996.

MacINTYRE, A. After virtue: a study in moral theory. London: Duckworth, 1981.

O'NEILL, O. Acting on orinciple: an essay on Kantian ethics. New York: Columbia University Press, 1975.

O'NEILL, O. Constructions of reason: explorations of Kant's practical philosophy. New York: Cambridge University Press, 1989.

O’NEILL, O. As perplexidades morais do alívio da fome. In: BONJOUR, L.; BAKER, A. Filosofia: textos fundamentais comentados. Porto Alegre: Artmed, 2010. p. 441-455.

TUGENDHAT, E. Lições de ética. Petrópolis: Vozes, 1993. 
WOOD, A. Humanity as end in itself. In: GUYER, P. Kant's groundwork of the metaphysics of morals: critical essays. Maryland: Rowman \& Littlefield Publishers, Inc. 1998. p. 165-187.

WOOD, A. Kant's ethical thought. Cambridge: Cambridge University Press, 1999.

Recebido: 12/08/2011

Received: 08/12/2011

Aprovado: 23/01/2012

Approved: 01/23/2012 